\title{
Diagnosis, Treatment and Outcomes of Patients with Aortopulmonary Window
}

\author{
İbrahim Halil Demir ${ }^{1}$, Abdullah Erdem ${ }^{1}$, Türkay Sarıtaş ${ }^{1}$, Fadli Demir ${ }^{1}$, Nurdan Erol', illker Kemal Yücel ${ }^{1}$,
} Numan Ali Aydemir², Ahmet Çelebi'

${ }^{1}$ Department of Pediatric Cardiology, Dr. Siyami Ersek Thoracic and Cardiovascular Surgery Training and Research Hospital, istanbul, Turkey ${ }^{2}$ Department of Pediatric Cardiac Surgery, Dr. Siyami Ersek Thoracic and Cardiovascular Surgery Training and Research Hospital, İstanbul, Turkey

\begin{abstract}
Background: Aortopulmonary window (APW) is a communication between the ascending aorta and the pulmonary artery in the presence of two separate semilunar valves and is the rarest of septal defects.
\end{abstract}

Aims: To present our experience with the diagnosis and outcome of APW cases.

Study Design: Retrospective cohort study.

Methods: Between June 2003 and October 2011, thirteen patients were diagnosed with APW. Clinical features of patients, findings of echocardiographic and angiographic examination, results of surgical intervention and follow-up were reviewed retrospectively.

Results: Eleven children (10 days to 16 years), underwent surgical correction of APW. In a 12-month-old boy, the defect was repaired by the transcatheter approach. In addition to APW repair, closure of VSD was performed in 2 patients. APW were associated with interruption in two patients; one also had a complex pathology. None of the patients died due to complications of surgical or transcatheter procedures. After a median follow-up period of 40 months, the patients were asymptomatic and none of them required additional medication, except for the patient with complex pathology including an interrupted aortic arch, who underwent balloon angioplasty for recoarctation.

Conclusion: In any infant with the findings of congestive heart failure and failure to thrive, APW must be kept in mind as a differential diagnosis. In isolated APW cases before 6 months of age, echocardiography is often sufficient for diagnosis. In complex cases, cardiac catheterisation is performed for the comprehensive evaluation of associated defects. After 6 months, cardiac catheterisation could be utilised to perform vasoreactivity testing and, if possible, to close the defect.

Key Words: Aortopulmonary window, pulmonary hypertension, aortopulmonary septal defect

Received: 16.05 .2012

Accepted: 27.12.2012

\section{Introduction}

Aortopulmonary window (APW) is a communication between the ascending aorta and pulmonary artery in the presence of two separate semilunar valves. It constitutes 0.15 $0.6 \%$ of all congenital heart anomalies and is the rarest of septal defects (1). APW may present itself as an isolated defect or with associated anomalies such as interrupted aortic arch, transposition of the great arteries and tetralogy of Fallot $(2,3)$. The disease causes increased pulmonary blood flow that leads to congestive heart failure, pulmonary hypertension and failure to thrive, depending on the size of the defect. Pulmonary vascular obstructive disease may develop rapidly in patients with unrestrictive defects. The prognosis of untreated cases with large defects is poor, with $40 \%$ fatality in the first year of life $(3,4)$. Early management is life-saving, either with surgical or transcatheter routes $(5,6)$. In this study, we aimed to present our experience in the diagnosis, treatment and outcomes of APW cases.

\section{Materials and Methods}

Thirteen patients with the diagnosis of APW, between June 2003 and October 2011, were reviewed. Clinical, telecardiographic, electrocardiographic and echocardiographic data of the patients in the pre-operative period were analysed. Also, angiographic findings of patients who had cardiac catheterisation were documented. The surgical techniques and intensive care follow-up data in the postoperative period were revisited (Tables 1 and 2). A pre-discharge echocardiographic examination was performed for all patients. In addition, echocardiographic examinations were repeated at the first and sixth months and performed annually thereafter. Ethical clearance was obtained from the hospital and local ethics committee.

\section{Surgical Technique}

After median sternotomy, aortic and bicaval cannulation was performed paying special attention to place the arterial 
Table 1. Demographic features of complex cases

\begin{tabular}{|c|c|c|c|c|c|c|c|c|c|c|}
\hline $\begin{array}{l}\text { Patient } \\
\text { No. }\end{array}$ & Age & Sex & $\begin{array}{l}\text { Weight } \\
\text { (kg) }\end{array}$ & $\begin{array}{l}\text { Type of } \\
\text { APW }\end{array}$ & $\begin{array}{c}\text { Follow-up } \\
\text { (months) }\end{array}$ & $\begin{array}{l}\text { Concomitant } \\
\text { anomaly }\end{array}$ & Catheter & Qp:Qs & $\begin{array}{c}\text { Aorta/PA } \\
\text { pressures } \\
\text { (mean) }\end{array}$ & Final status \\
\hline 1 & 2 months & $\mathrm{F}$ & 4.8 & Proximal & 40 & VSD & & & & $\begin{array}{l}\text { Mild MR } \\
\text { and } A R\end{array}$ \\
\hline 2 & 12 years & $M$ & 26 & Proximal & 35 & VSD & + & 2.4 & $80 / 45$ & Good \\
\hline 3 & 30 days & $\mathrm{F}$ & 3.4 & Distal & 12 & IAA, HT, PDA & + & & $74 / 70$ & $\begin{array}{c}\text { BA for } \\
\text { re-coarctation }\end{array}$ \\
\hline 4 & - & $\mathrm{F}$ & $2 \mathrm{~kg}$ & Intermediate & 11 & $\begin{array}{c}\text { DORV } \\
\text { (Fallot type) }\end{array}$ & + & & $46 / 17$ & $\begin{array}{c}\text { Not operated. } \\
\text { EX }\end{array}$ \\
\hline 5 & 10 days & $\mathrm{F}$ & 3.5 & Total & 6 & IAA & + & & $81 / 75$ & Good \\
\hline
\end{tabular}

Table 2. Demographic features of simple cases

\begin{tabular}{|c|c|c|c|c|c|c|c|c|c|c|}
\hline $\begin{array}{l}\text { Patient } \\
\text { No. }\end{array}$ & Age & Sex & $\begin{array}{l}\text { Weight } \\
\text { (kg) }\end{array}$ & $\begin{array}{c}\text { Type of } \\
\text { APW }\end{array}$ & $\begin{array}{l}\text { Follow-up } \\
\text { (months) }\end{array}$ & $\begin{array}{l}\text { Concomitant } \\
\text { anomaly }\end{array}$ & Catheter & Qp:Qs & $\begin{array}{c}\text { Aorta/PA } \\
\text { pressures } \\
\text { (mean) }\end{array}$ & Final status \\
\hline 1. & 16 years & M & 51 & Proximal & 84 & PFO & + & 2.4 & $92 / 78$ & Good \\
\hline 2. & 12 months & $\mathrm{F}$ & 7.5 & Distal & 80 & - & - & & & Good \\
\hline 3. & 11 months & $M$ & 7 & Proximal & 65 & - & + & 3 & $85 / 75$ & Good \\
\hline 4. & 4 months & $\mathrm{F}$ & 5.9 & Proximal & 49 & ASD & - & & & Good \\
\hline 5. & 6 months & M & 5 & Proximal & 48 & ASD & - & & & Good \\
\hline 6. & 5 months & $\mathrm{F}$ & 5.6 & Proximal & 25 & - & - & & & Good \\
\hline 7.* & 12 months & $M$ & 7.8 & Intermediate & 12 & PFO, PLSVC & + & 2 & $78 / 28$ & Good \\
\hline 8. & 2 months & M & 4.2 & Total & 6 & - & - & & & Good \\
\hline
\end{tabular}

cannula as distal as possible on the ascending aorta just below the brachiocephalic trunk origin. Branches of the right and left pulmonary arteries were controlled with snares, and the snares were tightened as the cardiopulmonary by-pass was initiated to avoid excessive blood flow to the lungs and inadequate blood flow to visceral organs while the patient was cooled to $28^{\circ} \mathrm{C}$. The heart was arrested using antegrade blood cardioplegia. APW and coronary ostia were evaluated by an oblique aortotomy that was extended to the non-coronary sinus. APW was repaired using politetrafloroethylene patch in eight patients (PTFE-GORETEX; W.L. Gore and Associates, Flagstaff, $A Z$, USA) with $5 / 0$ polypropylene suture and glutaraldehydetreated pericardial patch in three patients with $6 / 0$ polypropylene suture who had a lower body weight and thus, a smaller defect size. In two cases, ventricular septal defect (VSD) was closed by the transatrial approach using a Gore-tex patch.

In the patient with a right pulmonary artery emerging from right posterior ascending aorta (hemitruncus) with a concomitant type $A$ interrupted aorta and patent ductus arteriosus (PDA), distal ascending aortic and pulmonary arterial cannulations proximal to the PDA were performed for the arterial flow. As the cardiopulmonary bypass was initiated, the snares around the pulmonary branches were tightened while the patient was cooled to $20^{\circ} \mathrm{C}$. Following aortic cross-clamping and cardioplegic arrest, the right pulmonary artery was transected from the aorta and re-implanted to the main pulmonary trunk. The defect in the aorta was repaired using a pericardial patch. The aortic cannula was positioned in to the brachiocephalic trunk and the silastic tapes around the branches of the arcus were tightened. During antegrade cerebral perfusion, ductal tissue was totally removed and the descending aorta and arcus aorta was anastomosed. As the anatomy of aorta was re-established, the aortic cannula was withdrawn to the aorta shifting from antegrade cerebral perfusion to total body circulation following meticulous de-airing. In all patients, cardiopulmonary bypass was terminated after haemofiltration during the period of re-warming. The mean duration of cardiopulmonary by-pass was $67 \pm 23$ minutes, and the mean duration of cross-clamping was $42 \pm 31 \mathrm{~min}$.

\section{Results}

The age of diagnosis was between 7 days and 16 years (median 5 months). The body weight of patients was between 2 and $51 \mathrm{~kg}$ (median $5.2 \mathrm{~kg}$ ). Six patients were male. The median age at the time of operation was 5 months (ranged between 10 days and 16 years). Dyspnoea, tacyhpnoea and failure to thrive were the most common symptoms at pre- 
sentation for neonates and infants (11 patients). Two adolescent patients who were diagnosed at adolescence had been referred to our department because of heart murmurs. Demographic features of the patients are presented at Tables 1 and 2. Definitive diagnoses in ten patients were made by transthoracic echocardiography. Cardiac catheterisation was performed in three cases in order to document concomitant cardiac anomalies. In two patients with delayed diagnosis (ages at diagnosis of 16 and 12 years), cardiac catheterisation was performed to assess the operability because of pulmonary arterial hypertension at the systemic level. In another two cases, cardiac catheterisation was performed for transcatheter closure of the defect.

One of the cases had a concomitant interrupted aortic arcus, a right pulmonary artery originating from the ascending aorta (hemitruncus) and a PDA. This association is also known as Berry syndrome (7). The smallest patient, diagnosed at seven days old, also had interruption. Two patients had concomitant VSDs and three cases had atrial septal defects (ASDs) accompanying APW. Two cases had patent foramen ovale (PFO). In the patient with Cornelia De Lange syndrome (Case 4 in Table 1), APW accompanied a double outlet right ventricle (Fallot type). To the best of our knowledge, this was the first APW case in the literature associated with double outlet right ventricle and was published by our centre as a case report (8). In that case, it was realised that APW was compensating with low pulmonary blood flow due to pulmonary stenosis; thus, watchful waiting until the date of total repair was planned (Figure 1). However, this patient died before the total repair because of aspiration pneumonia, which was attributed to additional neurological afflictions.

In our case series, none of the patients with APW died due to factors related to APW per se or treatment-related complications. In a 12 month-old infant with restrictive APW, the defect was closed via percutaneous route (Case 7 in Table 2). Cardiac catheterisation revealed pulmonary artery pressure of $35 / 19$ (mean 28) mmHg. Pulmonary to systemic blood flow ratio was 2. Diameter of the defect was $4.7 \mathrm{~mm}$. Since the cineangiographic images revealed that the defect was in an optimal distance to the aortic valve and ostia of coronary arteries, we closed the defect via the transcatheter route using a muscular VSD device that was $6 \mathrm{~mm}$ in diameter (Figure 2). Repeated echocardiographic examination after procedure documented that the localisation of the device was optimal; the patient was discharged on $5 \mathrm{mg} / \mathrm{kg}$ acetyl salicylic acid treatment. After an uneventful follow-up period, neither a residual shunt through the defect nor a device-related stenosis in the pulmonary artery was detected. Angiography of an 11 month-old patient revealed that the defect of the patient was not at an optimal distance from aortic valve and coronary ostia. Thus, the defect was repaired surgically (Case 3 in Table 2).

Defects of eleven patients with APW were repaired by surgical techniques; the transaortic route was preferred in all patients. An artificial patch was used in eight patients and pericardium was utilised in three patients. None of the patients died. Seven cases were extubated in the first 48 hours. Three patients experienced pulmonary hypertensive crisis. The duration of ventilation was prolonged, and nitric oxide and prostacyclin was used in the treatment. In the patient with interruption, PDA and hemitruncus, repair of the APW was accompanied by arcus reconstruction, ligation of PDA and reconstruction of the right pulmonary artery in the same surgical session. This patient was discharged on the $43^{\text {rd }}$ post-op day because of severe pulmonary hypertension. Two other patients with pulmonary hypertension-related delayed weaning were extubated on the $5^{\text {th }}$ and $7^{\text {th }}$ days. These two patients

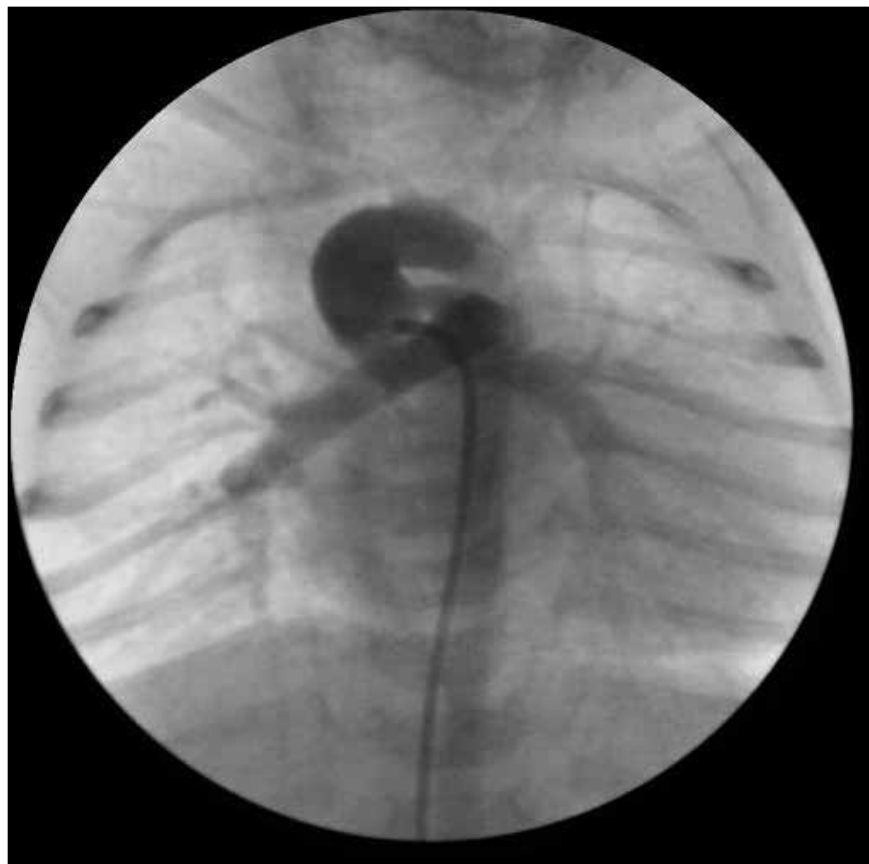

Figure 1. APW, functioning like an aortopulmonary shunt, accompanying the double outlet right ventricle (Fallot type) in a patient with Cornelia De Lange syndrome

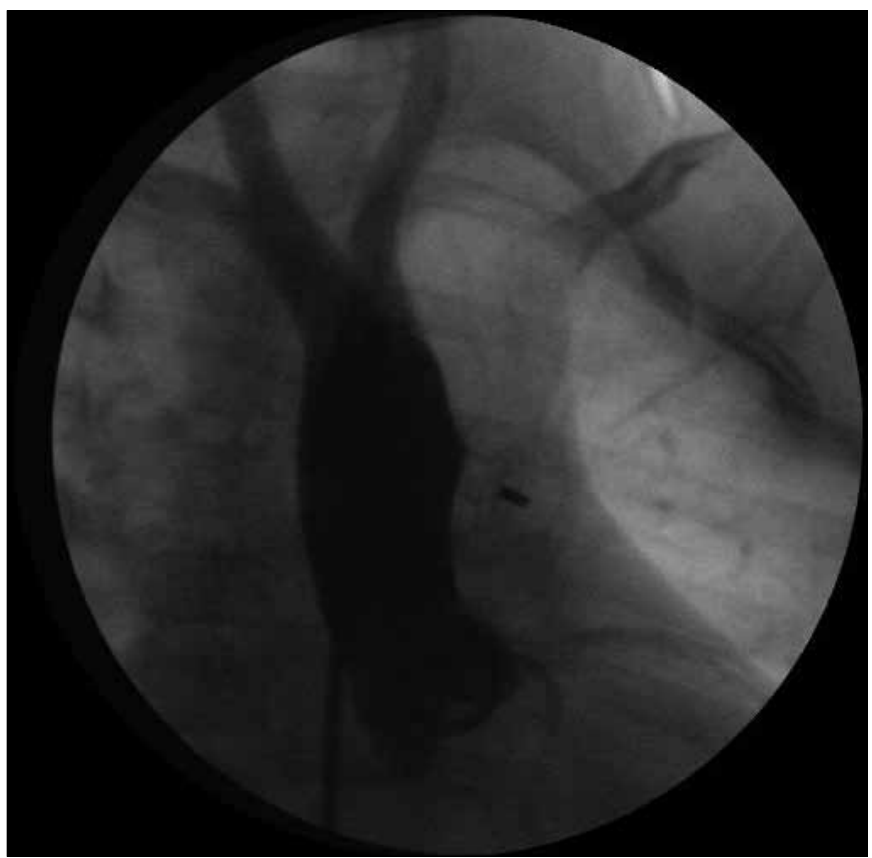

Figure 2. Aortagram after closure of aortopulmonary window with a muscular ventricular septal defect occluder 


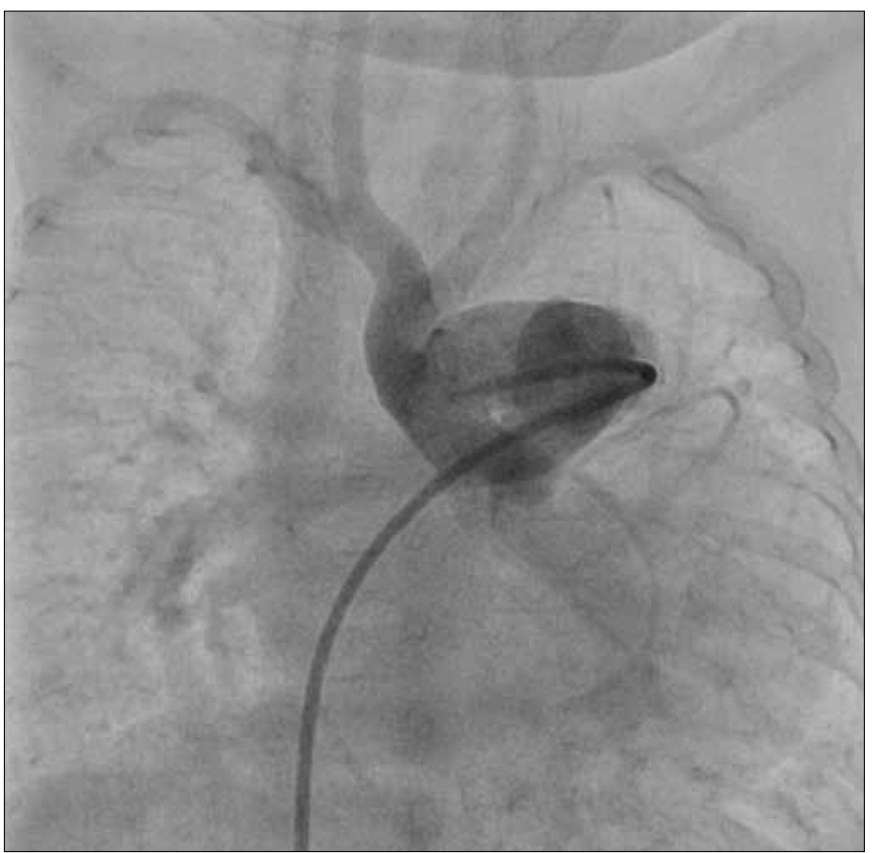

Figure 3. Angiogram of aortopulmonary window associated with interruption (case 13)

were documented to have findings of pulmonary hypertension during pre-operative assessment. Patches of PFO and ASD were left partially patent, on purpose.

Vasoreactivity testing of a 16 year-old case yielded a decrease in pulmonary vascular resistance, from 7.2 to 6.5 wood units. Echocardiographic examination of this patient in the postoperative period indirectly documented that pulmonary artery pressures declined to the normal range. Cardiac catheterisation demonstrated that systemic arterial pressure of the 12 year-old patient was $80 \mathrm{mmHg}$ and that pulmonary arterial pressure was $45 \mathrm{mmHg}$. Postoperative follow-up indirectly showed that pulmonary arterial pressures were in the normal range.

The median follow-up period was 40 months, ranging between 6 months and 84 months. Balloon angioplasty was performed in the aforementioned patient with type $A$ interrupted aorta because of re-coarctation developed in the $6^{\text {th }}$ postoperative month.

\section{Discussion}

APW is a communication between the ascending aorta and pulmonary artery in the presence of two separate semilunar valves. Mori et al. (9) identified three anatomical types of APW, namely proximal, distal and total. Ho et al. (10) modified this classification system by adding the intermediate type. These classification systems have improved the selection of cases eligible for transcatheter repair with sufficient superior and inferior rims; we also utilised this classification system in our cases.

The majority of cases with APW present with findings of congestive heart failure. Pulmonary hypertension due to massive pulmonary blood flow is the other main problem. Small defects which rarely culminate in congestive heart failure or pulmonary hypertension pose the risk of infective endocarditis. The most common clinical features of patients presenting especially in the neonatal period or infancy (11 patients) were dyspnoea, tachypnoea and failure to thrive.

In the past, cardiac catheterisation was the modality of choice in the diagnosis of APW. However, transthoracic echocardiography is currently preferred by the majority. When echocardiographic examination fails to detect an intracardiac pathology despite dilatation of the left heart chambers, which is indicative of volume overload, APW should be considered. The communication between the aorta and the pulmonary artery may best be visualised by transthoracic echocardiography at high parasternal short axis (11). High pulmonary arterial pressure and pulmonary vascular resistance may hamper the detection of the defect by colour Doppler and echocardiographic findings may be misinterpreted unless APW is considered in the differential diagnosis (12). In addition, pulmonary vascular resistance lowered by oxygen may improve Doppler signals. Accordingly, it is reported that, $100 \%$ oxygen delivered by mask may lower pulmonary vascular resistance and Doppler signals may be easier to obtain (13).

Cardiac catheterisation is necessary in APW cases older than 6 months of age with unrestrictive defects. In cases with associated complex pathologies, cardiac catheterisation may have to be performed earlier to elucidate the anatomic and hemodynamic features more comprehensively in the preoperative period. After 6 months, catheterisation is utilised to perform vasoreactivity testing and, if possible, to close the defect. Three of our cases had diagnostic catheterisation due to the complexity of cardiac pathology (Cases 3, 4 and 5 in Table 2). Two patients, diagnosed in the adolescence period, had pulmonary hypertension documented by transthoracic echocardiography. In these two patients, catheterisation was performed for pulmonary vasoreactivity testing. The surgery was successful in both cases. Two cases with delayed diagnosis did not experience any additional problem in the early postoperative period.

It is reported that coronary artery anomalies accompany $5-10 \%$ of cases $(14,15)$. Diagnosis of these patients in the preoperative period may be challenging. However, checking the ostia of coronary arteries during the operation may preclude further problems. None of our cases have anomalies of the coronary ostia.

Gross et al. (16) published the first successful APW repair. Following their report, numerous surgical techniques were developed. These techniques constituted either transaortic or transpulmonary approaches with or without patch use (17-19). Currently, several institutes prefer a technique developed by Johansson et al. (20). In this technique, APW is approached anteriorly and ridges of the defect are approximated by using an artificial patch. Thus, the artificial patch is sandwiched between the pulmonary artery and aorta (sandwich technique). Erez et al. (13), in order to prevent the potential residual defects, dissected the aorta and pulmonary artery entirely and repaired both arteries by using pericardial patches. We preferred the transaortic approach in our cases because coronary orifices are visualised better and reconstruction of both arteries is safer by this technique; we did not experience any complications. Similarly, Mert 
et al. (21) reported that they did not document residual defects when they preferred the transaortic approach. For the patch, we use either glutaraldehyde-treated autologous pericardium, or Gore-Tex of $0.4 \mathrm{~mm}$ thickness. We totally agree with surgical observation of Mert et al. (21), as there appeared to be no difference between these two materials in the follow-up period. However, we also share their opinion that the Gore-Tex patch may be more suitable, as it is a more solid material than the pericardium to work under systemic pressures, therefore preventing any possible late aneurysmal transformation.

APW with concomitant interrupted arcus aorta and right pulmonary artery originating from the ascending aorta is a very rare combination. In that case, repair of the hemitruncus and interrupted aorta was performed in the same surgical session. Also, PDA was divided and PFO was left patent. Due to associated pathologies and postoperative pulmonary hypertension, the patient was discharged on the $43^{\text {rd }}$ day.

Cardiac catheterisation was planned for the patient with restrictive type APW in her first year. The systemic to pulmonary flow ratio was 2 . Both transoesophageal echocardiography and sineangiography documented that the defect was suitable for transcatheter closure. We preferred the muscular VSD device for closure because the edges of the device were the optimal distance from coronary ostia and aortic valve, which lowers the risk of embolisation. In the literature, APW repair by transcatheter route was published as case reports and successful results were documented with different devices $(5,6,22)$. The Amplatzer atrial septal occluder or duct occluder might be good alternatives in adults with large defects but not in infants, as they can protrude either to the aorta or the pulmonary artery. On the other hand, in the presence of pulmonary artery hypertension, it is better to use the muscular ventricular septal defect occluder with retention discs on both sides of the defect to prevent possible embolisation.

Angiography and TEE findings of the 11-month-old patient catheterised for transcatheter repair revealed an inferior rim deficiency (proximal defect). Since the device would not be at sufficient distances to the aortic valve and coronary ostia, the procedure was halted and the defect was repaired surgically.

In conclusion, in any infant with the findings of congestive heart failure and failure to thrive, APW must be kept in mind in the differential diagnosis. In isolated APW cases before 6 months of age, echocardiography is mostly enough for diagnosis. In complex cases, cardiac catheterisation is performed for the comprehensive evaluation of associated defects. After 6 months, whether the defect is complex or not, cardiac catheterisation must be utilised to perform vasoreactivity testing and, if possible, to close the defect. Although surgical closure is the primary option in APW cases, percutaneous therapy may be a good alternative in isolated cases with suitable rims.

Ethics Committee Approval: Ethics committee approval was received for this study.

Informed Consent: N/A.

Peer-review: Externally peer-reviewed.

Author contributions: Concept - I.H.D., A.E., A.Ç.; Design - A.Ç., i.H.D., i.K.Y.; Supervision - A.Ç., A.E.; Resource - N.E., F.D.; Materials - i.H.D., T.S.; Data Collection\&/or Processing - A.E., T.S.; Analysis\&/ or Interpretation - T.S., A.N.A.; Literature Search - I.H.D., N.E., F.D.; Writing - i.H.D., i.K.Y.; Critical Reviews - i.H.D., N.A.A., A.Ç.

Conflict of Interest: No conflict of interest was declared by the authors.

Financial Disclosure: No financial disclosure was declared by the authors.

\section{References}

1. Tiraboschi R, Salomone G, Crupi G, Manasse E, Salim A, Carminati $\mathrm{M}$, et al. Aortopulmonary window in the first year of life: report on 11 surgical cases. Ann Thorac Surg 1988;46:438-41. [CrossRef]

2. McElhinney DB, Reddy MV, Tworetzky W, Silverman NH, Hanley FL. Early and late results after repair of aortopulmonary septal defect and associated anomalies in infants $<6$ months of age. Am J Cardiol 1998;81:195-201. [CrossRef]

3. Backer $\mathrm{CL}$, Mavroudis C. Surgical management of aortopulmonary window: a 40 year experience. Eur J Cardiothorac Surg 2002;21:773-9. [CrossRef]

4. Tkebuchava T, Von Segesser LK, Vogt PR, Bauersfeld U, Jenni R, Künzli $A$, et al. Congenital aortopulmonary window: diagnosis, surgical technique and long term results. Eur J Cardiothorac Surg 1997;11:293-7. [CrossRef]

5. Atiq M, Rashid N, Kazmi KA, Qureshi SA. Closure of aortopulmonary window with amplatzer duct occluder device. Pediatr Cardiol 2003;24:298-9. [CrossRef]

6. Naik GD, Chandra VS, Shenoy A, Isaac BC, Shetty GG, Padmakumar $P$, et al. Transcatheter closure of aortopulmonary window using amplatzer device. Catheter Cardiovasc Interv 2003;59:402-5. [CrossRef]

7. Berry TE, Bharati S, Muster AJ, Idriss FS, Santucci B, Lev M, et al. Distal aortopulmonary septal defect, aortic origin of the right pulmonary artery, intact ventricular septum, patent ductus arteriosus and hypoplasia of the aortic isthmus: a newly recognized syndrome. Am J Cardiol 1982;49:108-16. [CrossRef]

8. Akdeniz C, Odemis E, Erdem A, Celebi A. Double outlet right ventricle and aortopulmonary window in a patient with Cornelia de Lange syndrome: a novel association. Genet Couns 2009;20:161-6.

9. Mori K, Ando M, Takao A, Ishikawa S, Imai Y. Distal type of aortopulmonary window: report of 4 cases. Br Heart J 1978;40:681-9. [CrossRef]

10. Ho SY, Gerlis LM, Anderson C, Devine WA, Smith A. The morphology of aortopulmonary window with regard to their classification and morphogenesis. Cardiol Young 1994;4:146-55. [CrossRef]

11. Balaji S, Burch M, Sullivan ID. Accuracy of cross-sectional echocardiography in diagnosis of aortopulmonary window. Am J Cardiol 1991;67:650-3. [CrossRef]

12. DiBella I, Gladstone DJ. Surgical management of aortopulmonary window. Ann Thorac Surg 1998;65:768-70. [CrossRef]

13. Erez E, Dagan O, Georghiou GP, Gelber O, Vidne BA, Birk E. Surgical management of aortopulmonary window and associated lesions. Ann Thorac Surg 2004;77:484-7. [CrossRef]

14. Agius PV, Rushworth A, Connolly N. Anomalous origin of left coronary artery from pulmonary artery associated with an aortopulmonary septal defect. Br Heart J 1970;32:708-10. [CrossRef]

15. Brouwer MHJ, Beaufort-Krol GCM, Talsma MD. Aortopulmonary window associated with an anomalous origin of the right coronary artery. Int J Cardiol 1990;28:384-6. [CrossRef]

16. Gross RE. Surgical closure of an aortic septal defect. Circulation 1952;5:858-83. [CrossRef]

17. Morrow AG, Greenfield LJ, Braunwald E. Congenital aortopulmonary septal defect. Clinical and hemodynamic findings, surgical technique and results of operative correction. Circulation 1962;25:463-76. [CrossRef]

18. Ravikumar E, Whight CM, Hawker RE, Celermajer JM, Nunn G, Cartmill TB. The surgical management of aortopulmonary window using the anterior sandwich patch closure technique. J Cardiovasc Surg 1988;29:629-32. 
19. Shatapathy P, Madhusudhana Rao K, Krishnan KV. Closure of aortopulmonary septal defect. J Thorac Cardiovasc Surg 1987;93:789-91.

20. Johansson L, Michaelsson M, Westerholm CJ, Aberg T. Aortopulmonary window: a new operative approach. Ann Thorac Surg 1978;25:564-7. [CrossRef]
21. Mert M, Paker T, Akcevin A, Cetin G, Ozkara A, Saltık L, et al. Diagnosis, management, and results of treatment for aortopulmonary window. Cardiol Young 2004;14:506-11. [CrossRef]

22. Trehan V, Nigam A, Tyagi S. Percutaneous closure of nonrestrictive aortopulmonary window in three infants. Catheter Cardiovasc Interv 2008;71:405-11. [CrossRef] 